\title{
Commentary: Thinking outside the (cardiac) box
}

\author{
Nathaniel B. Langer, MD, MSc, and Hiroo Takayama, MD, PhD
}

\footnotetext{
From the Division of Cardiac, Thoracic, and Vascular Surgery, College of Physicians and Surgeons, Columbia University, New York, NY.

Disclosures: Authors have nothing to disclose with regard to commercial support.

Received for publication Nov 10, 2018; accepted for publication Nov 12, 2018; available ahead of print Jan 7 , 2019.

Address for reprints: Hiroo Takayama, MD, PhD, College of Physicians and Surgeons, Columbia University, 177 Fort Washington Ave, 7GN-435, New York, NY 10032 (E-mail: ht2225@cumc.columbia.edu).

J Thorac Cardiovasc Surg 2019;157:e363-4

$0022-5223 / \$ 36.00$

Copyright (C) 2018 Published by Elsevier Inc. on behalf of The American Association for Thoracic Surgery https://doi.org/10.1016/j.jtcvs.2018.11.051
}

How many of us would consider the described patient a surgical candidate after seeing the images presented in this issue of the Journal by Drs Nguyen and Schaff? When the combination of severe mitral stenosis with heavy mitral annular calcification (MAC) and a porcelain aorta had precluded "standard" surgical procedures, the authors proceeded with a creative approach, a left atrial to left ventricular bypass using a valved conduit via a left thoracotomy. This is an innovative alteration in a technique originally described by Wright and colleagues. ${ }^{1,2}$

Severe MAC remains a vexing problem. A recent article in the Journal provides an excellent overview on this subject, elaborating on existing surgical techniques, including aggressive decalcification and complex annular reconstruction, "respect" approaches in which standard annuloplasty or replacement techniques are modified such that the calcification is avoided, and extraanatomic bypass. ${ }^{3,4}$ Extra-anatomic bypass, as described here, can be the only option when patients have mitral stenosis and untreatable, severe MAC. However, there are a number of potentially problematic technical points. (1) Re-circulation: a patient undergoing extra-anatomic bypass cannot have any significant mitral regurgitation, as this could create an intra-cardiac circuit and impair forward flow. Also, severe mitral stenosis with untreatable MAC is frequently accompanied by significant mitral regurgitation, limiting the applicability of this technique. (2) Parallel circulation: it is not clear how much flow passes through each arm of the parallel pathways (mitral valve vs valved-conduit), and low flow could lead to thrombosis and decreased durability of the valved conduit. (3) Low-pressure circulation: unlike arterial grafting, extra-anatomic bypass for this low-pressure system requires precise determination of bypass graft length and valve position to avoid graft kinking during the cardiac cycle or after chest closure, as well as obstruction compassionate use. hands.

\section{References} 147:e76-8. 555-66.

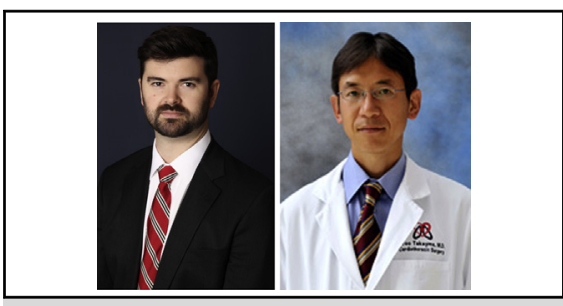

Nathaniel B. Langer, MD, MSc, and Hiroo Takayama, $\mathrm{MD}, \mathrm{PhD}$

Central Message

A left atrial to left ventricular bypass with a valved conduit via left thoracotomy is used to manage mitral stenosis in a challenging patient with severe annular calcification.

See Article page e361.

of flow due to the geometry of the valve within the conduit. As the result of these challenges, as well as unknown long-term outcomes, extra-anatomic bypass is likely to remain a technique of last resort.

Beyond these open surgical techniques, percutaneous and hybrid approaches have been described for replacing the mitral valve in patients with untreatable MAC or those who are at high or prohibitive surgical risk., Unfortunately, patients with MAC have been excluded from most of the early studies of mitral specific transcatheter devices. However, registry data suggests that their use is technically feasible but associated with significant risk. ${ }^{7}$ More data are needed before percutaneous or hybrid approaches can be considered outside of trials or

This case report is an excellent example of innovation that does not rely on "new toys." As technology continues to improve, and both percutaneous and open valve replacement options evolve, we can aim for more surgical innovations with these "new toys." However, it is essential to remember that creative surgical problem solving is in our

1. Said SM, Schaff HV. An alternate approach to valve replacement in patients with mitral stenosis and severely calcified annulus. J Thorac Cardiovasc Surg. 2014;

2. Wright JS, Thomson DS, Warner G. Mitral valve bypass by valved conduit. Ann Thorac Surg. 1981;32:294-6.

3. Bedeir K, Kaneko T, Aranki S. Current and evolving strategies in the management of severe mitral annular calcification. J Thorac Cardiovasc Surg. 2019;157: 
4. Kobsa S, Takayama H. MAC: "mitral annular calcification" or a "modern approach to concept learning" in surgery. J Thorac Cardiovasc Surg. 2019;157: 568-9.

5. Eleid MF, Cabalka AK, Williams MR, Whisenant BK, Alli OO, Fam N, et al. Percutaneous transvenous transseptal transcatheter valve implantation in failed bioprosthetic mitral valves, ring annuloplasty, and severe mitral annular calcification. JACC Cardiovasc Interv. 2016;9:1161-74.
6. Lee R, Fukuhara S, George I, Borger MA. Mitral valve replacement with a transcatheter valve in the setting of severe mitral annular calcification. J Thorac Cardiovasc Surg. 2016;151:e47-9.

7. Guerrero M, Dvir D, Himbert D, Urena M, Eleid M, Wang DD, et al. Transcatheter mitral valve replacement in native mitral valve disease with severe mitral annular calcification: results from the first multicenter global registry. JACC Cardiovasc Interv. 2016;9:1361-71. 